\title{
Silicon Phosphorus Nitride, the First Ternary Compound in the Silicon-Phosphorus-Nitrogen System
}

\author{
H.-P. Baldus* \\ Bayer AG, ZF-FAF, $D$-5090 Leverkusen, Germany \\ W. Schnick ${ }^{\dagger}$ and J. Lücke \\ Institut für Anorganische Chemie der Universität Bonn, \\ Gerhard-Domagk-Str. 1, D-5300 Bonn, Germany \\ U. Wannagat and G. Bogedain

\begin{abstract}
Institut für Anorganische und Analytische Chemie der Technischen Universität, Hagenring 30, D-3300 Braunschweig, Germany
\end{abstract}

Received December 16, 1992. Revised Manuscript Received April 5, 1993

\begin{abstract}
The novel compound $\mathrm{SiPN}_{3}$ has been prepared by reacting hexachloro- $N$-silylphosphinimine $\mathrm{Cl}_{3} \mathrm{Si}-\mathrm{N}=\mathrm{PCl}_{3}$ with liquid ammonia at $-78^{\circ} \mathrm{C}$ followed by subsequent removal of the ammonium chloride byproduct and annealing of the resulting polymeric imide at $800^{\circ} \mathrm{C}$ for $12 \mathrm{~h}$. The compound has been characterized by elemental analysis and ${ }^{29} \mathrm{Si}$ and ${ }^{31} \mathrm{P}$ MAS-NMR, as well as X-ray powder diffraction methods. The powder data suggest a defect Wurtzite type structure which is closely related to the structures of $\mathrm{Si}_{2} \mathrm{~N}_{2} \mathrm{O}$ and $\mathrm{Si}_{2} \mathrm{~N}_{2} \mathrm{NH}$. (Rietveld analysis data: space group $C m c 2_{1}, Z=4, a=902.4(4) \mathrm{pm}, b=527.5(2) \mathrm{pm}, c=469.8(2) \mathrm{pm} ; 44$ reflections observed; scan range $10^{\circ}<2 \vartheta<81^{\circ}$; germanium monochromator, $\mathrm{Cu} \mathrm{K} \alpha_{1}, R(\mathrm{wp})=0.047, R(I, h, k, l)=$ 0.071.) At $920^{\circ} \mathrm{C} \mathrm{SiPN}_{3}$ decomposes into $\mathrm{Si}_{3} \mathrm{~N}_{4}, \mathrm{P}_{4}$, and $\mathrm{N}_{2}$. The $\mathrm{Si}_{3} \mathrm{~N}_{4}$ obtained on pyrolysis of $\mathrm{SiPN}_{3}$ consists of a pure $\alpha$-phase and has an extremely low oxygen content.
\end{abstract}

\section{Introduction}

Recently, nitride ceramic materials have gained increased interest owing to their excellent mechanical properties, which are often superior to those of oxide ceramics. In particular their high bending strength, excellent thermal shock resistance, and high hardness makes them attractive engineering materials. Up to now only the binary nitrides of the light elements boron, aluminum, and silicon have been considered for these applications and therefore have been extensively studied. ${ }^{1-3}$

For reasons of analogy the light main-group-element phosphorus should in principle be suitable too for preparation of binary or ternary solid-state nitrides. However, a systematic synthetic approach to this class of compounds was made impossible for a long time by the unavailability of pure, single-phase, defined, and crystalline binary $\mathrm{P}_{3} \mathrm{~N}_{5}$. Recently, Schnick et al. have developed a new synthetic route for this compound. ${ }^{4}$ They have started a large-scale investigation on syntheses, characterization, and structure determination of binary phosphorus nitride $\left(\mathrm{P}_{3} \mathrm{~N}_{5}\right)$ as well as its ternary and quaternary compounds in combination with electropositive elements (e.g., hydrogen and alkali and alkaline-earth metals) using various techniques (singlecrystal and powder XRD, ED, HRTEM, EXAFS, IR, ${ }^{15} \mathrm{~N}$ and ${ }^{31} \mathrm{P}$ MAS-NMR, impedance spectroscopy, and thermal methods)..$^{4-10}$ Structural investigations revealed $\mathrm{PN}_{4}$

\footnotetext{
* Address correspondence to this author.

† New address: Laboratorium für Anorganische Chemie der Unversität Bayreuth, D-8580 Bayreuth, Germany.

(1) Mazdiyasni, K. S.; Cooke, M. J. Am. Chem. Soc. 1973, 56, 628.

(2) Mazdiyasni, K. S.; Ruh, R. J. Am. Chem. Soc. 1981, 64, 415.

(3) Lee, R.-R. J. Am. Ceram. SOc. 1991, 74, 2242.

(4) Schnick, W.; Lücke, J. Z. Anorg. Allg. Chem. 1992, 610, 121.

(5) Schnick, W.; Lücke, J. J. Solid State Chem. 1990, 87, 101.
}

tetrahedra to be typical building units of phosphorus nitrides. These units may be interconnected via common vertices to exhibit varying degrees of condensation. In analogy to structural features of well-known phosphates and silicates isosteric $\mathrm{P}-\mathrm{N}$ partial structures are formed: simple $\mathrm{PN}_{4}{ }^{7-}$ anions have been found in $\mathrm{Li}_{7} \mathrm{PN}_{4},{ }^{5}$ cyclotriphosphate, or silicate-type $\mathrm{P}_{3} \mathrm{~N}_{9}{ }^{12-}$ rings occur in $\mathrm{Li}_{12} \mathrm{P}_{3} \mathrm{~N}_{9},{ }^{11}$ and a $\mathrm{P}_{4} \mathrm{~N}_{10}{ }^{10}$ cage analogously to molecular phosphorus $(\mathrm{V})$ oxide $\left(\mathrm{P}_{4} \mathrm{O}_{10}\right)$ has been recently found in $\mathrm{Li}_{10} \mathrm{P}_{4} \mathrm{~N}_{10}{ }^{7}$ In $\mathrm{HPN}_{2}$ and LiPN $\mathrm{N}_{2}$ three-dimensional networks ${ }_{\infty}^{3}\left[\mathrm{PN}_{4 / 2}^{-}\right]$topologically identical to and isoelectronic with $\beta$-crystobalite have been found, 4,8 and infinite chains of corner-sharing $\mathrm{PN}_{4}$ tetrahedra ${ }_{\infty}^{1}\left[\mathrm{PN}_{2} \mathrm{~N}_{2 / 2}{ }^{4}\right]$ occur in $\mathrm{PN}_{3}{ }^{10}$ Even sodalite-type $\mathrm{PN}_{2}$ framework structures have recently been found ${ }^{10}$ and have been modified in several ways. To develop new engineering ceramic materials based on phosphorus nitrides, we tried to stabilize the $\mathrm{P}-\mathrm{N}$ bond which usually breaks at temperatures above $1000^{\circ} \mathrm{C}$ by introducing elements like silicon, aluminum, and boron.

Previous attempts to synthesize such novel ternary nitrides by means of solid-state reaction of the corresponding binary nitrides failed owing to the very small self-diffusion coefficients of those compounds and their incongruent melting behavior. Therefore we developed a new concept of preparation for these materials starting

(6) Schnick, W.; Lücke, J. Solid State Ionics 1990, 38, 271.

(7) Schnick, W.; Berger, U. Angew. Chem., Int. Ed. Engl. 1991, 30, 830.

(8) Schnick, W.; Lücke, J. Z. Anorg. Allg. Chem. 1990, 588, 19.

(9) Schnick, W.; Lücke, J. Angew. Chem., Int. Ed. Engl. 1992, 31, 213.

(10) Schnick, W. Phosphorus Sulfur, in press.

(11) Fast Powder Diffractometer System, STOE STADI/P, STOE \& CIE., Darmstadt, F.R.G., 1988. 
from molecular precursors having the stoichiometries and molecular structures desired in the final ceramic material.

After a polymerization step at low temperatures, a polymeric material is obtained exhibiting a homogeneous distribution of the participating elements. Owing to the short diffusion length provided, a homogeneous distribution on a molecular level allows statistical ordering of the different elements at moderate temperatures, resulting in a new multinary phase. Hence, this concept should work even for materials having very small self-diffusion coefficients in the final state.

In the present work the performance of this approach is demonstrated for the synthesis of the novel compound $\mathrm{SiPN}_{3}$.

\section{Experimental Section}

General Procedure. All operations were carried out in an inert atmosphere enclosure (MBraun Inert Gas Systems Model MB 150-GII) or in a standard Schlenk line. Infrared spectra were recorded on a Bruker FTIR 113V spectrometer; solids as $\mathrm{KBr}$ pellets or as double mulls (Nujol); liquids as capillary films. NMR experiments with liquid compounds were conducted on a Varian XL 200 spectrometer using $\mathrm{CDCl}_{3}$ as solvent and as an internal standard in case of ${ }^{1} \mathrm{H} N \mathrm{NMR}$. ${ }^{29} \mathrm{Si}$ spectra were recorded using TMS as an internal standard whereas $85 \%$ aqueous $\mathrm{H}_{3} \mathrm{PO}_{4}$ was used as an external standard in ${ }^{31} \mathrm{P}$ NMR measurements. Solid-state MAS-NMR spectra of ${ }^{31} \mathrm{P}$ and ${ }^{29} \mathrm{Si}$ nuclei were recorded on a Bruker WM 300 spectrometer. DTA, TG, and mass spectrometric measurements were carried out simultaneously in nitrogen from room temperature to $1600^{\circ} \mathrm{C}$ at $5^{\circ} \mathrm{C} /$ min with a Netzsch STA 429 thermobalance system.

The elemental analyses were accomplished at the Bayer analytical laboratories. Phosphorus and silicon were determined by ICP-AES using an acid digestion technique in order to dissolve the samples. Oxygen, nitrogen, and carbon analyses were carried out with Ströhlein Instruments ON-mat 822 and CS-mat 625, respectively.

Oxygen and carbon were detected as $\mathrm{CO}$ and $\mathrm{CO}_{2}$, respectively, in an infrared radiation sensor. Nitrogen was detected with a heat conductivity sensor. Metallic impurities were also detected with the aid of ICP-AES technique.

Transmission electron microscopy and scanning electron microscopy (Philips CM 20) equipped with an EDAX system and coupled with an electron beam diffraction facility were employed for morphology examination, crystal-phase detection, and quantitative elemental analysis, as well as electron beam diffraction on microscopic single crystals.

Crystallographic Measurements and Structure Determination. X-ray powder diffraction measurements were performed on a STOE STADI/P transmission powder diffractometer ${ }^{12}$ in Debye-Scherrer mode using sealed $0.3-\mathrm{mm}$ capillaries. Diffraction intensities were recorded by a small linear positionsensitive proportional counter (Mini-PSD, STOE) ${ }^{12}$ covering a $2 \vartheta$ range of $6.7^{\circ}$. A curved germanium monochromator was used to obtain a focused monochromatized $\mathrm{Cu} \mathrm{K} \alpha_{1}$ primary beam $(\lambda$ $=154.056 \mathrm{pm}$ ). Thus during an exposure time of $12 \mathrm{~h}$ in a $2 \vartheta$ range of $10-81^{\circ}$, sufficiently high counting rates and a total number of 44 reflections were obtained. For the structure refinement step intensities were used with an angular resolution of about $0.06^{\circ}$. All calculations were carried out using the STOE STADI/P software package..$^{11}$

Materials. Ammonia 5.0 (Messer Griesheim, $\mathrm{O}_{2}<5 \mathrm{ppm}$, $\mathrm{H}_{2} \mathrm{O}<15 \mathrm{ppm}$ ) was used as received; $\mathrm{SiCl}_{4}$ and hexamethyldisilazane (Bayer AG) were redistilled before use. $\mathrm{PCl}_{3}$ (Merck Schuchardt) was used as received. All the solvents were purified and dried by standard procedures before use.

Synthesis of $\mathrm{SiPN}_{3}$. Synthesis of $\mathrm{Cl}_{3} \mathrm{Si}-\mathrm{N}=\mathrm{PCl}_{3}(\mathrm{~A})$. The synthesis of $\mathrm{Cl}_{3} \mathrm{Si}-\mathrm{N}=\mathrm{PCl}_{3}$ is performed according to a procedure described by Filonenko et al. ${ }^{12,13}$
Synthesis of $\operatorname{SiPN}_{3}(B)$. A $4000-\mathrm{mL}$ four-necked roundbottomed flask, equipped with a dropping funnel, pressure filter funnel, gas inlet, pressure release valve, and a mechanical stirrer is loaded with ca. 2.5 -L anhydrous ammonia at $-70^{\circ} \mathrm{C}$. Compound A $(472 \mathrm{~g}, 1.66 \mathrm{~mol})$ dissolved in $500 \mathrm{~mL}$ of hexane is added dropwise to the ammonia within $2 \mathrm{~h}$ under vigorous stirring. A vigorous reaction occurs during which white fumes evolve and a white solid precipitates. The reaction mixture is stirred for an additional $2 \mathrm{~h}$ at $-78^{\circ} \mathrm{C}$ and then the white precipitate is filtered off in a stream of argon using a pressure filter funnel. After filtration the $\mathrm{NH}_{4} \mathrm{Cl}$ produced by the ammonolysis reaction is extracted with liquid $\mathrm{NH}_{3}$ for 4 days. The remaining white powder is dried under reduced pressure at $150^{\circ} \mathrm{C}$ in order to remove the rest of absorbed ammonia. A white powder is obtained with the following elemental analysis: Si $19.2 \%$ (18.4\%); P $22.0 \%$ (20.4\%); N 50.5\% (55.3\%); H 5.9\% (5.9\%); Cl 0.1\%, O $1.3 \%$. The values given in parentheses are calculated for the formula SiPN(NH)(NH2) 4. The deviation between the observed and calculated values regarding the nitrogen content is most probably due to moisture contamination and subsequent loss of ammonia during handling of this very moisture-sensitive material.

For pyrolysis, samples of the as-received powder are placed into a boron nitride boat and inserted into a quartz tube equipped with two ground glass joints. Before use the quartz tube has to be heated to $400^{\circ} \mathrm{C}$ in vacuum in order to remove the adsorbed water from the walls.

All loading operations are performed in a $\mathrm{N}_{2}$-filled glovebox, using $\mathrm{N}_{2}$ which is purified in-line over molecular sieves, $\mathrm{P}_{2} \mathrm{O}_{5}$ and $\mathrm{Cr}$ (II) catalysts in an attempt to minimize $\mathrm{O}_{2}$ and $\mathrm{H}_{2} \mathrm{O}$ contamination (both $<0.3 \mathrm{ppm}$ ). The powder samples are pyrolyzed in a programmable tube furnace. Initially that quartz tube is flushed with anhydrous $\mathrm{NH}_{3}$ at room temperature. The powder is heated under flowing anhydrous $\mathrm{NH}_{3}$ from room temperature to $800^{\circ} \mathrm{C}$ with a heating rate of $5^{\circ} \mathrm{C} / \mathrm{min}$ then held at that temperature for an additional $10-15 \mathrm{~h}$ and finally cooled to room temperature over at least $6 \mathrm{~h}$.

The material obtained this way is partially crystalline with a high degree of disorder. Elemental analysis: Si $27.1 \%(27.7 \%)$; P 29.3\% (30.7\%); N 41.4\% (41.6\%); H $1.1 \%$; Cl 0.03\%; O $0.4 \%$. These data are in accordance with the chemical composition $\mathrm{SiPN}_{3}$ (the calculated values are given in parentheses). The yield obtained corresponds to theoretical value calculated from the initial amounts of silicon and phosphorus, respectively. Toget a well-crystallized material the as-received powder is filled in a quartz tube together with a small amount of $\mathrm{NH}_{4} \mathrm{Cl}$ as crystallizing agent. The quartz tube is evacuated, sealed and the mixture is annealed at $900^{\circ} \mathrm{C}$ for an additional $24 \mathrm{~h}$. The pressure within the tube can be estimated from the amount of $\mathrm{NH}_{4} \mathrm{Cl}$ added by employing the ideal gas equation. To avoid risk of explosion, it should not exceed 10 bars. At the end of this procedure $\mathrm{NH}_{4} \mathrm{Cl}$ is removed by sublimation in vacuum.

\section{Results and Discussion}

Low-Temperature Ammonolysis of $\mathrm{Cl}_{3} \mathrm{Si}-\mathrm{N}=\mathrm{PCl}_{3}$ and Characterization of the Resulting Polymer. The starting compound $\mathrm{Cl}_{3} \mathrm{Si}-\mathrm{N}=\mathrm{PCl}_{3}$ is obtained in good yield $(86 \%)$ by a route according to Filonenko and Pinchuk. ${ }^{13}$

The ammonolysis reaction was carried out at $-78^{\circ} \mathrm{C}$ due to the high excess enthalpy expected for the reaction. To eliminate all chlorine functionalities, the phospinimine was dissolved in hexane and added dropwise to a large excess of liquid ammonia. We suggest a reaction according to eq 1 . After the removal of the ammonium chloride by

$$
\begin{aligned}
& x \mathrm{Cl}_{3} \mathrm{Si}-\mathrm{N}=\mathrm{PCl}_{3}+12 x \mathrm{NH}_{3} \rightarrow \\
& \quad\left\{\mathrm{SiPN}(\mathrm{NH})_{3-y}\left(\mathrm{NH}_{2}\right)_{2 y}\right\}_{x}+6 x \mathrm{NH}_{4} \mathrm{Cl} \quad(y=0-3)
\end{aligned}
$$

extraction with liquid ammonia a white, amorphous

(13) Filonenko, L. P.; Pinchunk, A. M. J. Gen. Chem. USSR 1979, 49, 
a)

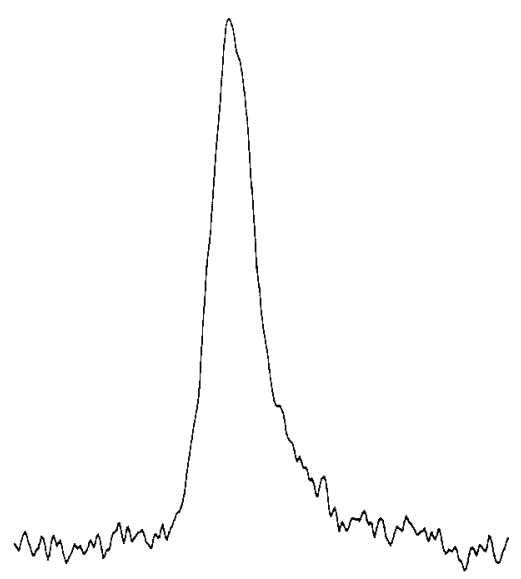

b)

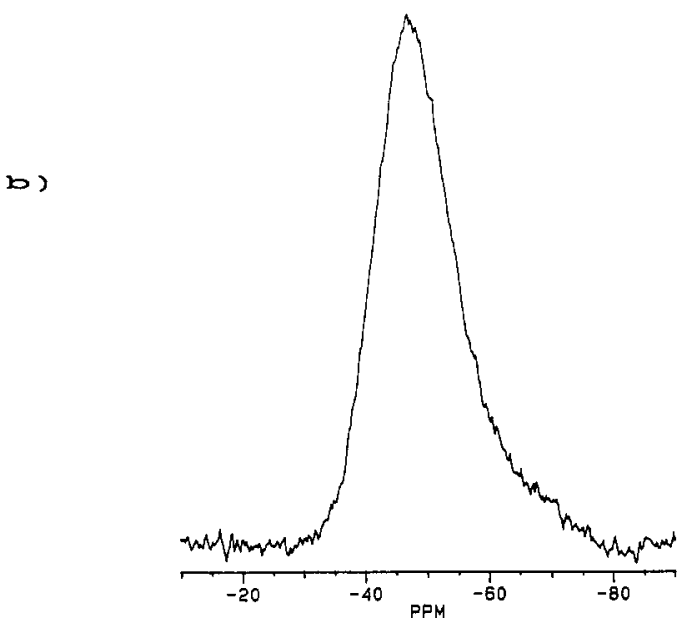

Figure 1. ${ }^{29} \mathrm{Si}$ NMR spectra of silicon phosphorus nitride materials: (a) amorphous polymer; (b) crystalline $\mathrm{SiPN}_{3}$.

powder is obtained. The analytical data of this material correspond to the chemical composition $\operatorname{SiPN}(\mathrm{NH})\left(\mathrm{NH}_{2}\right)_{4}$.

Due to the amorphous structure of the resulting phosphorus silicon imide-amide, ${ }^{29} \mathrm{Si}$ solid-state MASNMR spectra show a broad signal at ca. $-43 \mathrm{ppm}$ (Figure $1 a)$, indicating that silicon is tetrahedrally coordinated by nitrogen atoms. ${ }^{14}$ The polymeric compound exhibits two ${ }^{31} \mathrm{P}$ NMR signals at 25.3 and $14.7 \mathrm{ppm}$ (Figure 2a). Comparison of these data with ${ }^{31} \mathrm{P}$ NMR data of aminophosphazenes shows that the resonance at $14.7 \mathrm{ppm}$ can be assigned to $-\mathrm{N}=\mathrm{P}\left(\mathrm{NH}_{2}\right)_{2}-\mathrm{N}-$ moieties. ${ }^{15}$ Assuming that an enhanced cross-linking of the $\mathrm{P}-\mathrm{N}$ - network leads to a high-field shift of the ${ }^{31} \mathrm{P}$ resonances as is observed for phosphorus oxides, ${ }^{16}$ we can attribute the signal at $25.3 \mathrm{ppm}$ to $-\mathrm{N}=\mathrm{P}\left(\mathrm{NH}_{2}\right)_{3}$ - end groups. The IR spectrum of the polymer (Figure $3 \mathrm{a}$ ) shows five distinct regions. A band at $3440 \mathrm{~cm}^{-1}$ is attributed to the $\mathrm{NH}$ stretching vibration. At $2179 \mathrm{~cm}^{-1}$ we observe a combination mode of the $\mathrm{Si}-\mathrm{N}$ and $\mathrm{P}-\mathrm{N}$ vibrations. The IR absorption signal at $1636 \mathrm{~cm}^{-1}$ represents the $\mathrm{N}-\mathrm{H}$ deformation vibration. The broad band between 1450 and $1200 \mathrm{~cm}^{-1}$ can be assigned to the $\mathrm{P}=\mathrm{N}-\mathrm{P}$ asymmetric stretches whereas the signal at $940 \mathrm{~cm}^{-1}$ is attributed to the $\mathrm{Si}-\mathrm{N}$ stretching vibration. The high wavenumber of

(14) Carduner, K. R.; Carter III, R. O.; Milberg, M. E.; Crosby, G. M. Anal. Chem. 1987, 59, 2794.

(15) Crutchfield, M. M.; Dungan, C. H.; Letcher, J. H.; Mark, V.; Van Wazer, J. R. ${ }^{31}$ P Nuclear Magnetic Resonance. In Topics in Phosphorus Chemistry; John Wiley: New York, 1968; Vol. 5.

(16) Losso, P.; Schnabel, B.; Jäger, C.; Sternberg, U.; Stachel, D.; Smith, D. O. J. Non-Cryst. Solids 1992, 143, 265.
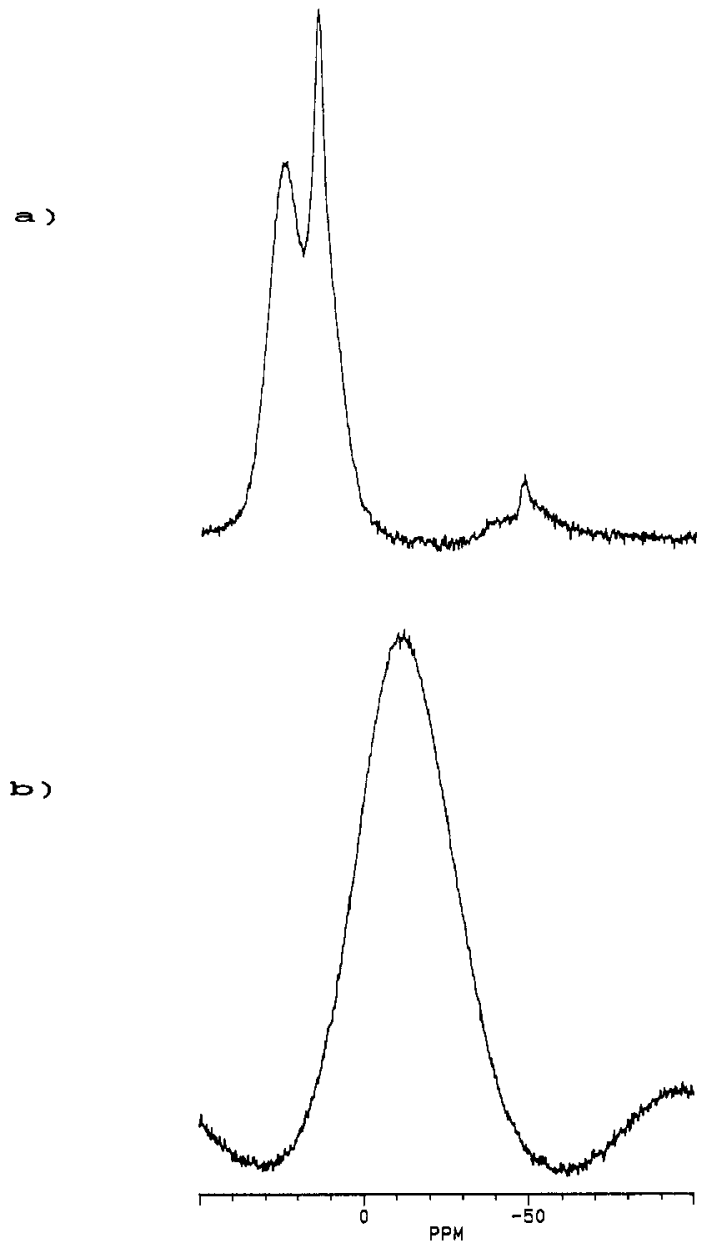

Figure 2. ${ }^{31} \mathrm{P}$ NMR spectra of silicon phosphorus nitride materials: (a) amorphous polymer (the badly resolved peaks at -50 ppm are spinning sidebands of the major peaks); (b) crystalline $\mathrm{SiPN}_{3}$.

the $\mathrm{P}-\mathrm{N}$ stretching vibration is consistent with an enhanced $\mathrm{PN}$ bond order and a bond polarity $+\mathrm{P}-\mathrm{N}-.17$

Synthesis and Characterization of $\mathrm{SiPN}_{3}$. On heating the preceramic polymer in a flow of ammonia at $800^{\circ} \mathrm{C}$ for at least $10 \mathrm{~h}$ we obtain partially crystalline $\mathrm{SiPN}_{3}$. Ammonia is the preferred atmosphere since it enhances the crystallinity of the sample. Nearly complete crystallization can be achieved by annealing the polymeric imide at $900^{\circ} \mathrm{C}$ for $24 \mathrm{~h}$ using ammonium chloride as a mineralizing agent. According to TGA/DTA measurements performed in nitrogen between room temperature and $1600{ }^{\circ} \mathrm{C}$, the conversion of the polymer to the crystalline compound is accompanied by a weight loss of about $28 \%$ in the range between 150 and $900^{\circ} \mathrm{C}$ (Figure 4a). The pyrolysis gases evolved during this stage consist only of ammonia as revealed by simultaneous mass spectrometric analyses. Therefore we conclude according to eq 2 that this loss of ammonia is owing to further polycondensation until the composition of stoichiometric $\mathrm{SiPN}_{3}$ is achieved.

$$
\operatorname{SiPN}(\mathrm{NH})\left(\mathrm{NH}_{2}\right)_{4} \rightarrow \mathrm{SiPN}_{3}+3 \mathrm{NH}_{3}
$$

The theoretical weight loss of $26.8 \%$ matches closely the observed value which gives further evidence to the above proposed reaction scheme.

(17) Wannagat, U.; Burgdorf, D.; Bürger, H.; Pawelke, G. Z. Naturforsch. 1991, 46b, 1039 . 


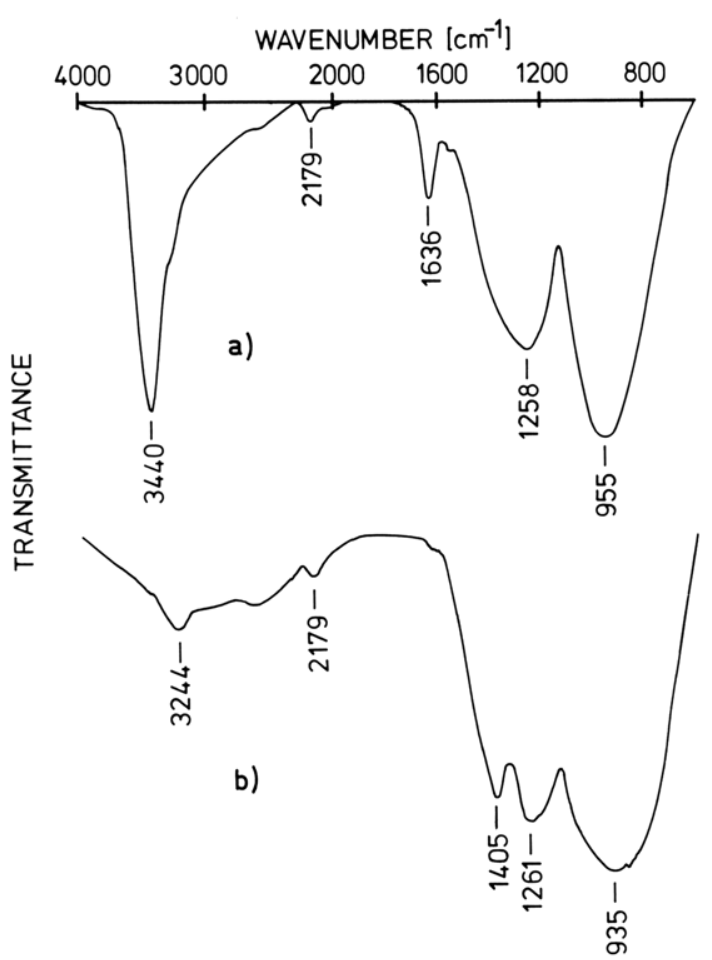

Figure 3. IR spectra of silicon phosphorus nitride materials: (a) amorphous polymer; (b) crystalline $\mathrm{SiPN}_{3}$.
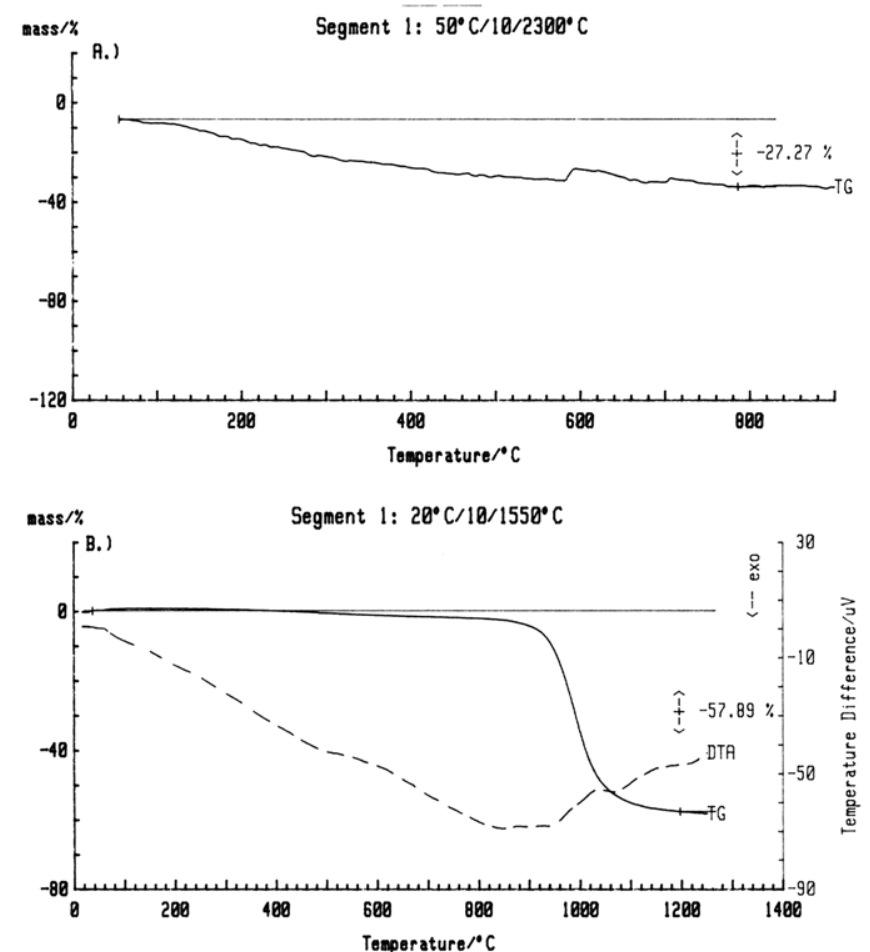

Figure 4. TG/DTA plots of silicon phosphorus nitride materials: (a) TG/DTA curve of the amorphous polymer between room temperature and $900^{\circ} \mathrm{C}$; (b) TG/DTA curve of crystalline $\mathrm{SiPN}_{3}$ between 900 and $1500^{\circ} \mathrm{C}$.

Electron microscopic analyses (TEM/EDAX) on microscopic single crystals show a Si:P ratio of 1:1. SEM micrographs reveal well-defined crystals with a size in the range from 5 to $50 \mu \mathrm{m}$ (Figure 5). The signal of the ${ }^{29} \mathrm{Si}$ MAS NMR spectrum is observed at $-46 \mathrm{ppm}$ (Figure $1 \mathrm{~b}$ ). This value is close to the ${ }^{29} \mathrm{Si}$ NMR signal of silicon nitride ${ }^{18}$ and can therefore be attributed to silicon atoms tetrahe-

(18) Carduner, K. R.; Hatfield, G. R. J. Mater Sci. 1989, 24, 4209.

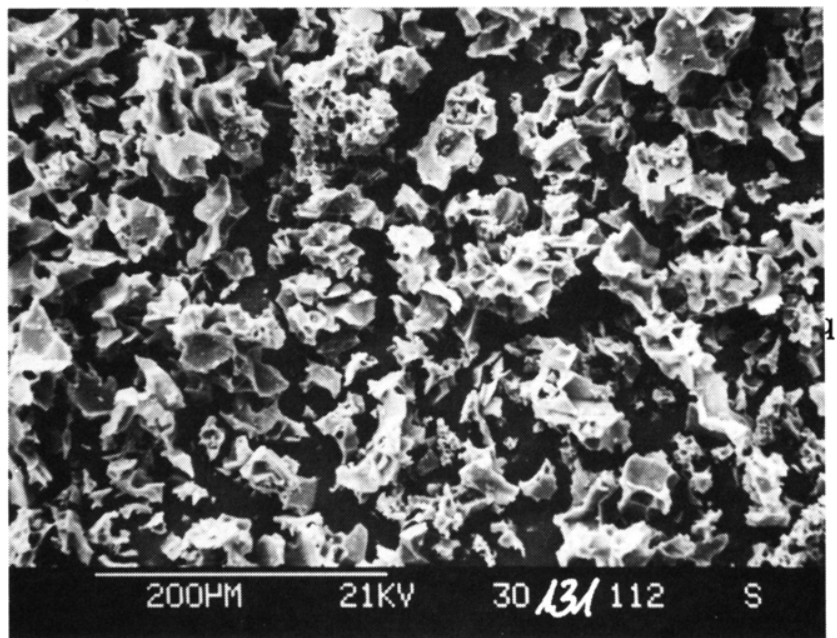

Figure 5. Scanning electron micrograph of microcrystalline $\mathrm{SiPN}_{3}$.

drally coordinated by nitrogen. Compared to the value of the ${ }^{29} \mathrm{Si}$ resonance in the preceramic polymer the observed high-field shift suggests an increased degree of cross linking of the material. The ${ }^{31} \mathrm{P}$ NMR resonance of the crystalline $\mathrm{SiPN}_{3}$ is detected at $-12 \mathrm{ppm}$ (Figure $2 \mathrm{~b}$ ).

This value fits well into the series of polymeric $\mathrm{P}-\mathrm{N}$ compounds such as $\mathrm{LiPN}_{2}, \mathrm{HP}_{4} \mathrm{~N}_{7}$, and $\mathrm{P}_{3} \mathrm{~N}_{5}$, containing three-dimensionally connected $\mathrm{PN}_{4}$ tetrahedra. The ${ }^{31} \mathrm{P}$ NMR resonance is increasingly high-field shifted with increasing degree of cross-linking ( ${ }^{31} \mathrm{P}$ resonances: $\mathrm{LiPN}_{2}$ (0 ppm), $\mathrm{HP}_{4} \mathrm{~N}_{7}$ (-26 ppm), $\mathrm{P}_{3} \mathrm{~N}_{5}$ (-46 to $\left.\left.-65 \mathrm{ppm}\right)\right)^{19}$ This is in agreement with the crystal structure of the compound described below. The high-field shift of the ${ }^{31} \mathrm{P}$ signal $(35 \mathrm{ppm})$ after the conversion of the material from the polymeric state into the crystalline state is very large compared to the shift of the ${ }^{29} \mathrm{Si}$ signal (3 ppm) which may be due to the very large bandwidth of the ${ }^{31} \mathrm{P}$ resonances. The width of the ${ }^{31} \mathrm{P}$ NMR signal of about $50 \mathrm{ppm}$ may be due to the high degree of disorder in the crystalline state.

Infrared spectra of the crystalline solid (Figure $3 b$ ) show three main absorption bands. The weak absorption at $3440 \mathrm{~cm}^{-1}$ suggests the presence of residual $\mathrm{N}-\mathrm{H}$ groups in the solid. The shoulder at $1405 \mathrm{~cm}^{-1}$ as well as the bands at 1250 and $937 \mathrm{~cm}^{-1}$ can be assigned to the asymmetric $\mathrm{P}=\mathrm{N}-\mathrm{P}$ and $\mathrm{Si}-\mathrm{N}-\mathrm{Si}$ stretches respectively. The band at $2179 \mathrm{~cm}^{-1}$ is again due to a combination of $\mathrm{P}-\mathrm{N}$ and $\mathrm{Si}-\mathrm{N}$ stretches. A comparison of the $\mathrm{P}-\mathrm{N}=\mathrm{P}$ and $\mathrm{Si}-\mathrm{N}-\mathrm{Si}$ IR absorption bands of the amorphous polymer and the crystalline material shows no significant difference, indicating that the bonding situation and the short-range order in the solid in both the amorphous and the crystalline compound are rather similar. The similar width of the respective absorption bands of the amorphous and the crystalline solids is consistent with the assumption that the long-range order in the crystals is strongly disturbed.

Structure Determination. All of the observed X-ray reflections (Table I) could be indexed assuming orthorhombic symmetry and a C-centered Bravais lattice. The unit-cell dimensions of $\mathrm{SiPN}_{3}$ also were confirmed by electron diffraction on microscopic single crystals. Analysis of the observed powder pattern of $\mathrm{SiPN}_{3}$ (Figure 6)

(19) Schnick, W.; Lücke, J. Manuscript in progress.

(20) Peters, D.; Jacobs, H. J. Less-Common Met. 1989, 146, 241.

(21) Idrestedt, I.; Brosset, C. Acta Chem. Scand. 1964, 18, 1879. 


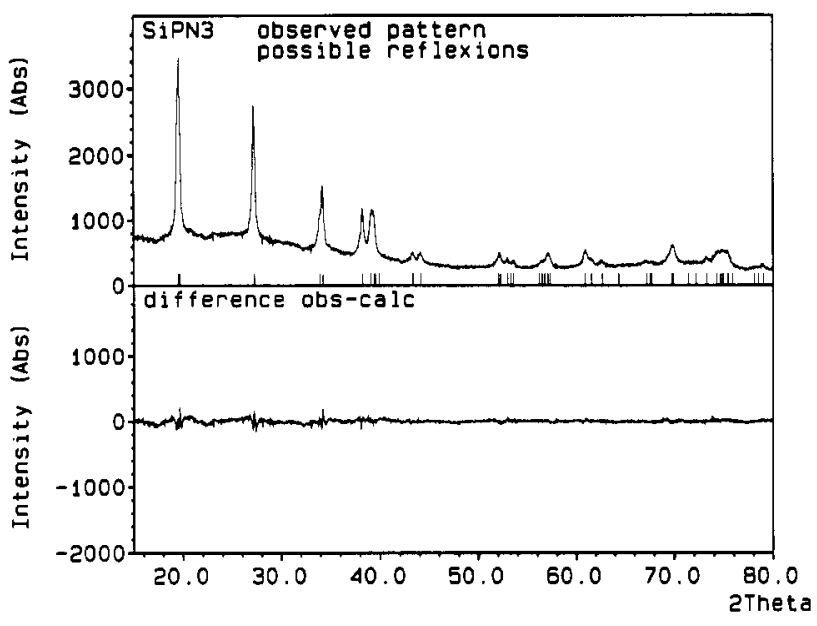

Figure 6. Powder diffraction pattern of $\mathrm{SiPN}_{3}$ showing the observed powder pattern and difference (bottom) pattern.

Table I. Observed and Calculated X-ray Reflections of $\mathrm{SiPN}_{3}\left(\mathrm{Cu} \mathrm{K} \alpha_{1}\right.$ Radiation, $\left.\lambda=154.056 \mathrm{pm}\right)$

\begin{tabular}{|c|c|c|c|c|c|c|}
\hline$h$ & $k$ & $l$ & $2 \vartheta$ & fwhm & $I_{\mathrm{obs}}$ & $I_{\text {calc }}$ \\
\hline 1 & 1 & 0 & 19.473 & 0.342 & 356.63 & 353.78 \\
\hline 2 & 0 & 0 & 19.657 & 0.325 & 912.45 & 857.01 \\
\hline 1 & 1 & 1 & 27.247 & 0.364 & 887.57 & 835.13 \\
\hline 0 & 2 & 0 & 33.956 & 0.399 & 106.61 & 139.18 \\
\hline 3 & 1 & 0 & 34.286 & 0.401 & 360.73 & 362.90 \\
\hline 0 & 0 & 2 & 38.281 & 0.422 & 353.25 & 330.54 \\
\hline 0 & 2 & 1 & 39.131 & 0.426 & 242.32 & 225.88 \\
\hline 3 & 1 & 1 & 39.422 & 0.428 & 328.49 & 294.19 \\
\hline 2 & 2 & 0 & 39.540 & 0.428 & 0.08 & 0.07 \\
\hline 4 & 0 & 0 & 39.925 & 0.430 & 2.14 & 1.04 \\
\hline 1 & 1 & 2 & 43.300 & 0.448 & 36.32 & 38.86 \\
\hline 2 & 0 & 2 & 43.389 & 0.448 & 44.16 & 47.71 \\
\hline 2 & 2 & 1 & 44.157 & 0.452 & 83.69 & 92.42 \\
\hline 0 & 2 & 2 & 52.089 & 0.494 & 55.05 & 52.85 \\
\hline 3 & 1 & 2 & 52.322 & 0.495 & 92.79 & 95.78 \\
\hline 1 & 3 & 0 & 53.007 & 0.499 & 52.82 & 44.58 \\
\hline 4 & 2 & 0 & 53.391 & 0.501 & 0.09 & 0.08 \\
\hline 5 & 1 & 0 & 53.621 & 0.502 & 56.45 & 50.95 \\
\hline 2 & 2 & 2 & 56.209 & 0.515 & 14.37 & 10.68 \\
\hline 4 & 0 & 2 & 56.505 & 0.517 & 41.92 & 36.87 \\
\hline 1 & 3 & 1 & 56.773 & 0.518 & 10.55 & 9.81 \\
\hline 4 & 2 & 1 & 57.140 & 0.520 & 79.28 & 80.06 \\
\hline 5 & 1 & 1 & 57.359 & 0.521 & 65.26 & 71.92 \\
\hline 3 & 3 & 0 & 60.977 & 0.540 & 151.05 & 139.24 \\
\hline 6 & 0 & 0 & 61.608 & 0.543 & 62.21 & 59.62 \\
\hline 1 & 1 & 3 & 62.677 & 0.549 & 43.30 & 47.10 \\
\hline 3 & 3 & 1 & 64.443 & 0.558 & 6.00 & 6.94 \\
\hline 1 & 3 & 2 & 67.251 & 0.573 & 20.80 & 31.29 \\
\hline 4 & 2 & 2 & 67.584 & 0.574 & 2.45 & 3.89 \\
\hline 5 & 1 & 2 & 67.783 & 0.575 & 10.76 & 17.59 \\
\hline 0 & 2 & 3 & 69.778 & 0.586 & 106.61 & 101.08 \\
\hline 3 & 1 & 3 & 69.974 & 0.587 & 132.52 & 129.01 \\
\hline 0 & 4 & 0 & 71.467 & 0.595 & 15.48 & 20.92 \\
\hline 6 & 2 & 0 & 72.244 & 0.599 & 14.68 & 20.43 \\
\hline 2 & 2 & 3 & 73.298 & 0.604 & 66.43 & 69.53 \\
\hline 3 & 3 & 2 & 74.327 & 0.610 & 110.42 & 103.13 \\
\hline 0 & 4 & 1 & 74.687 & 0.611 & 31.34 & 30.05 \\
\hline 6 & 0 & 2 & 74.902 & 0.613 & 67.26 & 64.81 \\
\hline 2 & 4 & 0 & 74.955 & 0.613 & 37.64 & 36.31 \\
\hline 5 & 3 & 0 & 75.401 & 0.615 & 32.97 & 33.40 \\
\hline 6 & 2 & 1 & 75.451 & 0.615 & 89.26 & 91.70 \\
\hline 7 & 1 & 0 & 75.909 & 0.618 & 0.11 & 0.17 \\
\hline 2 & 4 & 1 & 78.123 & 0.629 & 5.48 & 17.03 \\
\hline 5 & 3 & 1 & 78.563 & 0.632 & 8.23 & 9.23 \\
\hline 7 & 1 & 1 & 79.064 & 0.634 & 42.82 & 37.02 \\
\hline
\end{tabular}

revealed an analogy between the crystal structures of $\mathrm{SiPN}_{3}$ and that of $\mathrm{Si}_{2} \mathrm{~N}_{2} \mathrm{NH}$ or $\mathrm{Si}_{2} \mathrm{~N}_{2} \mathrm{O}$ (Table II).

On the basis of this analogy the crystal structure of $\mathrm{SiPN}_{3}$ was refined by the use of a modified version of the Rietveld full-profile method. ${ }^{11}$ For the structure refinement step intensities in the $2 \vartheta$ range $10-81^{\circ}$ were used with an angular resolution of about $0.06^{\circ}$. Due to the rather
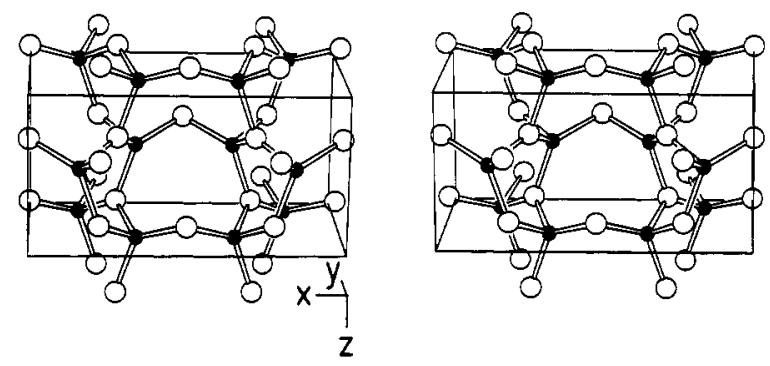

Figure 7. Crystal structure of $\mathrm{SiPN}_{3}$ (filled circles $=\mathrm{P}$, Si atoms, empty circles $=\mathrm{N}$ atoms).

Table II. Metric Similarities of the Unit Cells of $\mathrm{SiPN}_{3}$, $\mathrm{Si}_{2} \mathrm{~N}_{2} \mathrm{NH}$, and $\mathrm{Si}_{2} \mathrm{~N}_{2} \mathrm{O}$

\begin{tabular}{cccc}
\hline & $\mathrm{SiPN}_{3}$ & $\mathrm{Si}_{2} \mathrm{~N}_{2} \mathrm{NH}^{20}$ & $\mathrm{Si}_{2} \mathrm{~N}_{2} \mathrm{O}^{21}$ \\
\hline$a, \mathrm{pm}$ & $902.4(4)$ & $919.30(7)$ & $884.3(5)$ \\
$b, \mathrm{pm}$ & $527.5(2)$ & $540.96(4)$ & $547.3(5)$ \\
$c, \mathrm{pm}$ & $469.8(2)$ & $481.90(4)$ & $483.5(5)$
\end{tabular}

Table III. Fractional Coordinates and Isotropic Thermal Parameters $\left(\times 10^{4}\right)$ with ESDs for SiPN $_{3}$

\begin{tabular}{lccccc}
\hline atom & site & $x$ & $y$ & $z$ & $U$ (iso) \\
\hline $\mathrm{Si} / \mathrm{P}$ & $8 \mathrm{~b}$ & $3294(13)$ & $3406(34)$ & 0 & $95(34)$ \\
$\mathrm{N} 1$ & $8 \mathrm{~b}$ & $2859(35)$ & $3753(89)$ & $3556(52)$ & $25(108)$ \\
$\mathrm{N} 2$ & $4 \mathrm{a}$ & 0 & $2535(75)$ & $4225(109)$ & $25(108)$
\end{tabular}

Table IV. Selected Bond Distances (pm) and Angles (deg) (with ESDs) in $\mathrm{SiPN}_{3}$

\begin{tabular}{llll}
\hline $\mathrm{P} / \mathrm{Si}-\mathrm{N} 2$ & $165.8(20)$ & & \\
$\mathrm{P} / \mathrm{Si}-\mathrm{N} 1$ & $168.3(41)$ & $168.9(46)$ & $173.0(25)$ \\
$\mathrm{P} / \mathrm{Si}-\mathrm{N} 1-\mathrm{P} / \mathrm{Si}$ & $125.8(17)$ & $117.1(23)$ & $115.2(23)$ \\
$\mathrm{P} / \mathrm{Si}-\mathrm{N} 2-\mathrm{P} / \mathrm{Si}$ & $136.3(29)$ & &
\end{tabular}

symmetrical peak shape a modified Lorentzian function (Mod 2 Lorentzian) proved to be suitable for representation of the individual reflection profiles. The angular dependence of the peak full-width at half-maximum (fwhm) was described by a proper Tchebychev polynomial. The background intensity line was also refined during the calculation using a Tchebychev polynominal of up to the seventh degree. The integration range used was $6.0 \mathrm{fwhm}$ on both sides of the diffraction line positions. Refinement of the half-width parameters, the zero-point, and the scale factor was performed before the refinement of the positional parameters was started. The refinement of the crystal structure of $\mathrm{SiPN}_{3}$ was started on the basis of the similarity of the powder patterns of $\mathrm{SiPN}_{3}$ and $\mathrm{Si}_{2} \mathrm{~N}_{2} \mathrm{O}$ assuming a statistical distribution of $\mathrm{Si}$ and $\mathrm{P}$ on the silicon sites and with nitrogen on both of the anionic positions ( $\mathrm{N}$ and $\mathrm{O}$ ) in $\mathrm{Si}_{2} \mathrm{~N}_{2} \mathrm{O}$. Neither during the Rietveld refinement nor by electron diffraction on small single crystals of $\mathrm{SiPN}_{3}$ any experimental evidence for an ordered distribution of $\mathrm{Si}$ and $\mathrm{P}$ resulting in a superstructure (lower space-group symmetry or larger unit cell) occurred. The refinement (seven structural and three isotropic thermal parameters refined, 44 reflections observed) converged with final residual factors of $R(p)=0.0327$ and $R(\mathrm{wp})=$ 0.0472 for the profile and $R(I, h k l)=0.0710$ for the structure. Atomic coordinates of $\mathrm{SiPN}_{3}$ are summarized in Table III, interatomic distances and bonding angles are given in Table IV. Silicon phosphorus nitride $\mathrm{SiPN}_{3}$ exhibits a three-dimensional polymeric network structure of corner sharing $\mathrm{PN}_{4}$ and $\mathrm{SiN}_{4}$ tetrahedra (Figure 7). Analogously to $\mathrm{Si}_{2} \mathrm{~N}_{2} \mathrm{O}$ and $\mathrm{Si}_{2} \mathrm{~N}_{2} \mathrm{NH}$ the crystal structure derives from a defect Wurtzite-type arrangement. Thus two-dimensional planes of condensed $\mathrm{Si}_{3} \mathrm{~N}_{3}$ rings occur with half of the silicon atoms being replaced by phosphorus. The puckered six-membered rings show boat conforma- 
tion. The silicon and phosphorus atoms seem to be statistically distributed. By means of X-ray powder crystallography a distinction between phosphorus and silicon in $\mathrm{SiPN}_{3}$ was not possible. The infinite layers of condensed $(\mathrm{Si} / \mathrm{P})_{3} \mathrm{~N}_{3}$ rings perpendicular to the $a$ axis of the orthorhombic unit cell represent a distorted variant of typical Wurtzite-type layers. Condensation to a threedimensional network is achieved by the bridging nitrogen atoms (N2), each connecting two Wurtzite-type $(\mathrm{Si} / \mathrm{P}){ }_{3} \mathrm{~N}_{3}$ layers in $a$ direction saturating the remaining free valences of phosphorus and silicon, respectively.

Pyrolysis of SiPN $N_{3}$. Heating of the crystalline $\mathrm{SiPN}_{3}$ above $900^{\circ} \mathrm{C}$ in the TG/DTA apparatus (Figure 4b) leads to a significant weight loss of about $57.6 \%$ in the range $920-1100^{\circ} \mathrm{C}$. In this temperature range the pyrolysis gases contain mainly $\mathrm{P}_{4}$ and $\mathrm{N}_{2}$ according to the mass spectrometric data which are detected simultaneously during the TG/DTA experiment which gives strong evidence for a decomposition of $\mathrm{SiPN}_{3}$. The decomposition of the material is also indicated by an endothermic DTA signal at ca. $1000{ }^{\circ} \mathrm{C}$. According to X-ray measurements the $1000^{\circ} \mathrm{C}$ material is completely amorphous, indicating the breakdown of the $\mathrm{SiPN}_{3}$ structure in the solid.

On further pyrolysis up tp $1200{ }^{\circ} \mathrm{C}$ we observe an exothermic DTA signal at ca. $1100^{\circ} \mathrm{C}$. X-ray analysis of material heated at that temperature show a new diffraction pattern which corresponds to $\alpha-\mathrm{Si}_{3} \mathrm{~N}_{4}$. Thus we can assign the exothermic DTA signal to the crystallization of $\alpha$-silicon nitride. Elemental analysis data obtained on this material reveal a phosphorus content of only $200 \mathrm{ppm}$. In summary these data lead to the conclusion that the decomposition of $\mathrm{SiPN}_{3}$ occurs between 900 and $1000^{\circ} \mathrm{C}$ leading to an amorphous silicon nitride which finally crystallizes around $1100^{\circ} \mathrm{C}$. The corresponding reaction pathway is described in eq 3 . The theoretical weight loss

$$
\begin{aligned}
12 \mathrm{SiPN}_{3} \stackrel{900-1000^{\circ} \mathrm{C}}{\rightarrow} 4 \mathrm{Si}_{3} \mathrm{~N}_{4} \text { (amorphous) } & +3 \mathrm{P}_{4}+10 \mathrm{~N}_{2} \\
& \stackrel{1100^{\circ} \mathrm{C}}{\rightarrow} \alpha-\mathrm{Si}_{3} \mathrm{~N}_{4}
\end{aligned}
$$

for the decomposition of $\mathrm{SiPN}_{3}$ into $\mathrm{Si}_{3} \mathrm{~N}_{4}$ according to eq 3 amounts to $53.8 \%$. The observed weight loss of $57 \%$ is about $3 \%$ higher than the theoretical value. This discrepancy may be explained by the loss of residual $\mathrm{NH}$ groups and the removal of oxygen from the $\mathrm{SiPN}_{3}$ material during the decomposition. This hypothesis is consistent with the extremely low oxygen content (200-400 ppm) of our silicon nitride material derived from the decomposition of $\mathrm{SiPN}_{3}$. An explanation for this finding is that the gaseous phosphorus released from $\mathrm{SiPN}_{3}$ at temperatures above $900^{\circ} \mathrm{C}$ acts as an oxygen getter.

A second interesting feature is the high $\alpha$-phase content of such a SiPN ${ }_{3}$-derived material annealed at $1250^{\circ} \mathrm{C}$ for $3 \mathrm{~h}$, which is in the range from $98 \%$ to $100 \%$. The $\alpha$-phase content of conventionally synthesized crystalline silicon nitride is normally in the range $80-90 \%$. A further unusual property of our material is the high degree of sintering and Ostwald ripening of the $\alpha-\mathrm{Si}_{3} \mathrm{~N}_{4}$ crystals obtained on annealing at $1250^{\circ} \mathrm{C}$ for $3 \mathrm{~h}$ (Figure 8). Owing to the low oxygen content of the material, one would expect just the opposite effect, very small crystals with a narrow particle size distribution. A possible reason for this behavior is

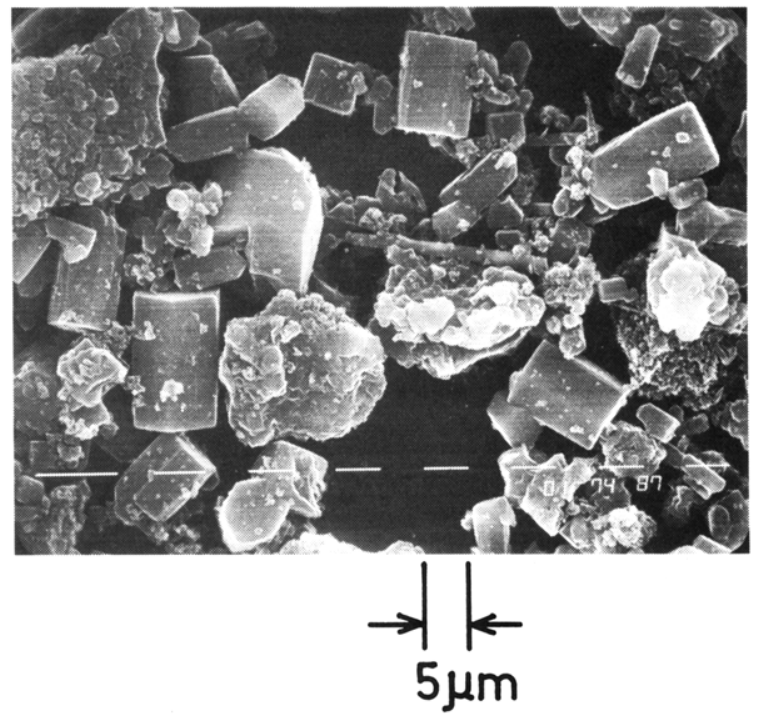

Figure 8. Scanning electron micrograph of $\alpha-\mathrm{Si}_{3} \mathrm{~N}_{4}$ derived from $\mathrm{SiPN}_{3}$ pyrolyzed at $1400{ }^{\circ} \mathrm{C}$ for $2 \mathrm{~h}$.

the formation of species with high diffusion coefficients during the breakdown of the $\mathrm{SiPN}_{3}$ structure (including $\mathrm{Si}-\mathrm{N}$ bond cleavage) between 900 and $1200{ }^{\circ} \mathrm{C}$. These species should cause a highly enhanced solid-state diffusion within the material which may lead to the observed sintering and Ostwald ripening effects.

\section{Conclusions and Outlook}

We have synthesized a novel ternary nitride, $\mathrm{SiPN}_{3}$, through tailoring a molecular precursor compound to the elemental stoichiometry of the desired final material. The structure of $\mathrm{SiPN}_{3}$ is isotypic to the structures of $\mathrm{Si}_{2} \mathrm{~N}_{2} \mathrm{O}$ and $\mathrm{Si}_{2} \mathrm{~N}_{2} \mathrm{NH}$. This observation may be rationalized by taking into account that $\mathrm{SiO}$ and $\mathrm{PN}$ are isoelectronic. ${ }^{17}$ Our experiments show that the $\mathrm{P}-\mathrm{N}$ bond in $\mathrm{SiPN}_{3}$ is not stabilized by the presence of silicon, and hence it is not suitable as a high-temperature ceramic by itself. Nevertheless, it may have some interesting applications in the field of the processing of non-oxide powders. Decomposition of $\mathrm{SiPN}_{3}$ at ca. $1000^{\circ} \mathrm{C}$ yields $\mathrm{Si}_{3} \mathrm{~N}_{4}$ and gaseous $\mathrm{P}_{4}$, which acts as an oxygen getter. Annealing the obtained $\mathrm{Si}_{3} \mathrm{~N}_{4}$ at $1250{ }^{\circ} \mathrm{C}$ for $3 \mathrm{~h}$ yields pure $\alpha-\mathrm{Si}_{3} \mathrm{~N}_{4}$ which can serve as a crystallizing agent. Therefore, calcination of commercially produced amorphous $\mathrm{Si}_{3} \mathrm{~N}_{4}$ together with small amounts of $\mathrm{SiPN}_{3}$ should lead to crystalline silicon nitride with a low oxygen content and a high amount of the desired $\alpha$-phase. On the other hand, considering the unexpected sintering effects observed at the crystalline $\mathrm{Si}_{3} \mathrm{~N}_{4}$ powder obtained from pyrolysis of $\mathrm{SiPN}_{3}$, this compound could also serve as a sintering additive for silicon nitride by promoting the solid state diffusion within the ceramic body. Experiments concerning these possible applications of $\mathrm{SiPN}_{3}$ are under way.

Acknowledgment. We thank Dr. L. Born and Dr. B. Wehrle, both from Bayer AG, for fruitful collaboration and discussions concerning the measurement and interpretation of X-ray and solid-state NMR-data, respectively.

Supplementary Material Available: Listing of the final Rietveld Refinement (4 pages). Ordering information is given on any current masthead page. 